Research Article

\title{
Causal Attributions as Correlates of Secondary School Students' Academic Achievement
}

\author{
Susan Ngunu (D), Theresia Kinai, Philomena Ndambuki, and Peter Mwaura \\ Department of Educational Psychology, Kenyatta University, P.O. Box 43844-00100, Nairobi, Kenya \\ Correspondence should be addressed to Susan Ngunu; ngunu.susan@ku.ac.ke
}

Received 8 May 2019; Revised 6 August 2019; Accepted 11 October 2019; Published 5 November 2019

Academic Editor: José Carlos Núñez

Copyright (C) 2019 Susan Ngunu et al. This is an open access article distributed under the Creative Commons Attribution License, which permits unrestricted use, distribution, and reproduction in any medium, provided the original work is properly cited.

The purpose of this study was to establish the relationship between causal attributions and academic achievement. Weiner's Model of Achievement Attribution guided this research. Five-hundred and eighty-five students (315 males, 270 females) participated in the study. The participants completed the Multidimensional Multiattributional Causality Scale (MMCS) while academic achievement was obtained from the participants' academic records. Majority of the students attributed both success and failure to internal, uncontrollable, and unstable attributions. The results indicated that causal attributions were significantly correlated to academic achievement. Taking into account that students can form maladaptive causal attributions, the study made recommendations to the stakeholders on intervention measures.

\section{Introduction}

In most educational systems, student's advancement is predicated on graded performance in a series of classes. One of the indicators of quality education is cognitive achievement of learners which is measured by test and examination scores [1]. Failure to achieve passing grades has numerous implications during secondary school and past students' overall individual achievement level. It undermines the students' opportunity of joining higher institutions of learning, jeopardizes their chance for job placement, and reduces the individual's active participation in nationwide development. This has resulted in many nations working towards improving the quality of education. Education in Kenya is key in the realization of the country's vision 2030. These objectives cannot be achieved in an environment of poor academic achievement. Even though measures have been taken to improve the quality of education in Kenya, majority of the students still perform poorly especially in national examinations according to the yearly reports by Kenya National Examination Council (KNEC). In 2016, only 88,929 (15.6\%) out of 577,253 students managed to attain C+ and above. This was a big drop from the results of 2015 according to the Ministry of Education [2]. During this period, Kiambu County contributed immensely to this declining performance, for instance, in 2016, there was total decline with only $18.3 \%$ managing a $\mathrm{C}+$ and above and the mean score recorded as 4.0 [2]. This poor performance has drawn the concern of the government, teachers, parents, and other stakeholders in education for it could be a barrier to the County's contribution to the national economic growth and participation in the nationwide development. These stakeholders have sought for answers to the question of continued mass failures especially in some secondary schools over the years.

Global and local studies have identified myriad factors which influence students' academic achievement such as family factors, teacher factors, students' attitudes, use of technology, interaction processes, characteristics of the students, and class among others [3-6]. However, poor performance has persisted necessitating the study of other variables that might account for the students' academic achievement. With a focus on causal attributions, the studies reviewed emphasize that causal attributions for failure and success are determinants of the student's academic achievement [7-12]. How a student reacts to whether they passed or failed depends upon their causal attributions. Considering that students may form unfavorable and biased 
attributions which may be associated with maladaptive academic behavior, they need to be trained and encouraged to form appropriate attributions that will make them hope and strive in academic achievement. Establishing students' causal attributions may therefore be important in understanding their academic achievement. In Kenya, scanty information exists on the relationship between causal attributions and academic achievement, yet causal attributions could be a major contributor for the dismal or low academic achievement in the population of study. Most of the studies conducted on the relationship of causal attributions and academic achievement are from America, Asia, and Europe. Generalization of results to the Kenyan population and context may not be feasible without an empirical investigation. It is on this premise that the current study was carried out to shed light on causal attributions as correlates of academic achievement among form three students in Kiambu County, Kenya.

To explain the causes for their success and failure in academic achievement, the students use causal attributions. According to Weiner's Model of Academic Achievement [13], student's future academic achievement can be significantly influenced by their causal attributions for their successes or failures. He argues that people have diverse attributional styles or specific reasons for explaining their academic outcomes based on three dimensions, namely, locus of causality, that is, whether the cause of outcome is from within the individual (internal) or from the external environment (external). Controllability means the extent to which the individuals perceive themselves as being able to influence a particular cause. If the factors are controllable, the students believe that they can change these causes but if they consider the causes as uncontrollable, it creates a perception that they cannot be easily changed. Finally, stability refers to the consistency in which causal attributions present and influence the results in similar situations. Stable attributions imply that students believe that every time they engage in the same task, the outcome of their performance will be similar. When the attributions are unstable, the implication is that when the behavior is performed the next time the outcome of performance may vary [12]. The theory argues that, when learners attribute their academic success to internal, unstable causes that they can control, they will be unrelenting on the academic tasks. According to this theory, if learners attribute success to internal factors such as ability, it generates positive academic motivation and behavior. Nevertheless, attributing success to external factors such as ease of the task or attribute failure to more stable, internal, and uncontrollable causes (innate ability) is detrimental to later motivation and achievement striving [13]. This attribution leads to more hopeless emotional response and lowered expectations for later success. Attributing failure to more unstable but controllable causes, for example, effort or strategy, therefore provides more opportunity for hopefulness and higher expectations for success in subsequent task since it creates a chance for potential change.

There are numerous related and empirical studies that link students' causal attributions to academic achievement.
These studies are centered on students' causal attributions styles for success or failure and their relationship on the actual academic achievement. Contradictory results have been found in studies carried out on the most common attribution styles to success and failure and the relationship between the students' attribution style and academic achievement. An investigation among 156 American college students on multiple causal attributions in performance in foreign language classes found that causal patterns were different between success and failure causes [14]. The students reported more external control for success than failure. In another study on causal attributions of academic achievement using college students in China with sample of 1400 , differences were found in the characteristics of causal attributions towards success and failure [9]. The study found that the characteristics of causal attributions towards success and failure were a significant parameter of grade. It also suggested that there were differences and similarities of causal attributions by students in primary and middle colleges. These differences were attributed to level of knowledge, maturity, and growth especially the cognitive maturity. Further, the study among 43 university students in Philippines showed that many students attributed their success on internal factors such as ability and effort [11]. This study further showed that for one to succeed, attributing academic performance to internal factors was better since it empowered the students unlike attributing to external factors. Another study [15] conducted among 205 high school students in Israel on academic causal attributions revealed that more students attributed failure to lack of ability than to lack of effort. Luck was attributed very infrequently. On the other hand, a study designed to make comparison between the academic outcomes of high and low attribution groups in Australia found that students who attributed their failure to external and uncontrollable factors usually considered themselves more helpless in the face of any academic related task [16]. Students were more likely to believe that future success was highly probable if they attributed their successes to high ability than when they attributed their success to other factors. In contrast, the attribution of an outcome to low ability makes future failure seem highly probable. There is more devastation when one thinks that failure is by virtue of low ability, than when one believes that failure is due to bad luck, task difficulty, or lack of effort.

In Africa, a study involving 260 Tanzanian university students examined the applicability of the attribution theory in understanding how students attribute their academic success and failure [17]. A questionnaire was used for collecting data. The results indicated that many of the students attributed their academic performance to internal, unstable, and controllable factors. High performing students attributed academic performance to internal causes than low performing students. In another study [10], the relationship between causal attributions and academic attainment was explored among college students in Nigeria. The study employed correlation research design involving 389 students. Surprisingly, the findings showed that there were no significant correlations recorded among the causal attribution factors and 
academic attainment of students apart from external attributions of failure, which reported a significant correlation. In Kenya, a comparative study [18] between teachers and students attributions regarding Mathematics achievement found that the students attributed their success mainly to internal causes (hard work, effort, and ability) while they attributed their failures mainly to external causes. However, most of these studies were carried out in a different cultural setting. The possibility of intervening cultural diversity made the current study necessary as it sought to provide more knowledge from empirical data in the population of study. The shortcoming of the local study was that it was a case study involving only one school and therefore, generalization of the findings may not have been appropriate to the population of the current study. The main purpose of this study was to establish the relationship between causal attributions and participants' academic achievement. The study further determined the best predictors of participants' academic achievement, given the twelve causal attributions dimensions. The study was guided by the following research hypotheses:

$\mathrm{H}_{\mathrm{a} 1}$ : there is a significant relationship between causal attributions dimensions of locus of causality and academic achievement

$\mathrm{H}_{\mathrm{a} 2}$ : there is a significant relationship between causal attributions dimensions of controllability and academic achievement

$\mathrm{H}_{\mathrm{a} 3}$ : there is a significant relationship between causal attributions dimensions of stability and academic achievement

$\mathrm{H}_{\mathrm{a} 4}$ : there is a significant prediction model of academic achievement from the causal attribution dimensions

\section{Methods}

The study employed correlational research design.

\section{Participants}

Participants were 585 (315 males, 270 females) form three students. The participants were aged between 13 and 21 years $(M=17, \mathrm{SD}=8.7)$. The participants were drawn from 10 secondary schools in Kiambu County, Kenya. The schools were categorized into national, extracounty, and subcounty schools. The researcher applied both stratified and simple random sampling techniques. Stratified sampling was used to divide the population into strata. The strata were used to select the schools based on whether they were national schools, extracounty, or subcounty schools and whether they were boys schools, girls schools, or coeducational schools (mixed). This method enabled the sizes of the samples from the different strata to remain proportional to the sizes of the strata. Proportional allocation is considered highly efficient and as the most favorable design since the rationale of sampling is mainly to estimate the population value of some characteristic [19]. Simple random sampling was used to select the 600 students from the sampled schools.

\section{Measures}

The Multidimensional Multiattributional Causality Scale (MMCS) a rating scale by Lefcourt et al. [20] was modified and used to collect the data on causal attributions of students. The MMCS consists of four factors, that is, effort, ability, task difficulty, and luck that were conceptualized into three distinctive dimensions, namely, locus of causality (internal and external), controllability (controllable and uncontrollable), and stability (stable and unstable) attributions. Ability was conceptualized as internal, uncontrollable, and stable and effort as internal, controllable, and unstable. On the other hand, luck was conceptualized as external, uncontrollable, and unstable while task difficulty as external, uncontrollable, and stable. Twelve subdimensions were derived from the three causal dimensions. From locus of causality are internal locus of causality attributions for success; internal locus of causality attributions for failure; external locus of causality attributions for success; and external locus of causality attributions for failure. From controllability are controllable attributions for success, controllable attributions for failure, uncontrollable attributions for success, and uncontrollable attributions for failure. Derived from stability are stable attributions for success, stable attributions for failure, unstable attributions for success, and unstable attributions for failure. Five-point likert scale, ranging from 1 (low) to 5 (high), was used for rating.

To measure the students' academic achievement, records from the two previous examination results were examined and an overall mean score was obtained. Seven subjects were tabulated for each student based on Kenya National Examination Council (KNEC) criteria of scoring and grading. The mean score for the seven subjects was calculated and overall mean for two consecutive terms tabulated for each student. The mean scores were transformed into standardized scores to make them comparable among the students in different schools.

\section{Procedures}

The first step of the study involved pilot testing the instruments of the study to ascertain reliability. To evaluate the reliability of the MMCS, Cronbach alpha $(\alpha)$ coefficient was computed for locus of causality, stability, and controllability dimensions. The reliability of the causal attribution measures for causal dimension of locus of causality, stability, and controllability was $0.78,0.78$, and 0.71 , respectively. The overall reliability coefficient for the Multidimensional Multiattributional Causality Scale (MMCS) of 0.75 was deemed adequate, and the scale was adopted. Relevant research authorization was sought before the commencement of the study. Permission to use the research instrument was sought from the authors. All the participants were treated in accordance with the American Psychological Association (APA) Ethical code. The researcher guided the participants on how to fill the questionnaire. The questionnaire was administered during a school day in the classroom setting, and it took 35-40 minutes to fill the questionnaire after 
which the researcher assisted by two research assistants collected the research tools. The class teachers provided the students' academic achievement scores from the official school records. The collected data were cleaned and coded for statistical analysis.

\section{Data Analysis}

The participant's causal attributions for success and failure in academic achievement were analyzed by use of descriptive statistics followed by hypothesis testing.

Descriptive statistics for the twelve dimensions of causal attributions are presented in Table 1. The results indicate that on the locus of causality, the students' perceived internal factors to greatly contribute to their success $(M=45.14$, $\mathrm{SD}=5.81)$ than the external factors $(M=15.12, \mathrm{SD}=4.84)$. The students tended to attribute success to factors within themselves. They perceived to have control over their success. Surprisingly, they also highly attributed their failure to internal causes $(M=37.78, \mathrm{SD}=5.93)$ than external factors $(M=22.26, \mathrm{SD}=5.05)$. Among controllability dimension, students were more likely to attribute success more to uncontrollable factors $(M=35.21, \mathrm{SD}=5.98)$ than to controllable factors $(M=20.09, \mathrm{SD}=3.72)$. Similarly, they were eager to attribute failure to uncontrollable attributions $(M=37.57, \mathrm{SD}=5.92)$ compared to controllable factors $(M=15.31, \mathrm{SD}=4.27)$.

On the other hand, the results on stability dimension show that the participants tended to attribute success more to unstable causes $(M=33.16, \mathrm{SD}=4.69)$ than to stable causes $(M=27.10, \mathrm{SD}=4.54)$. Failure was also highly attributed to unstable causes $(M=34.62, \mathrm{SD}=5.39)$ than to stable causes $(M=25.43, \mathrm{SD}=4.86)$. Interestingly, both success and failure among the participants were perceived to be mainly caused by internal, uncontrollable, and unstable causes.

\section{Hypotheses Testing}

Pearson's correlation coefficient was computed to establish the relationship between the three dimensions of causal attributions and academic achievement.

The following null hypotheses were tested:

$\mathrm{H}_{01}$ : there is no significant relationship between dimensions of locus of causality and academic achievement.

$\mathrm{H}_{02}$ : there is no significant relationship between dimensions of controllability and academic achievement.

$\mathrm{H}_{03}$ : there is no significant relationship between dimensions of stability and academic achievement.

Considering that each of the three dimensions of causal attributions had four subdimensions making a total twelve subdimensions, Pearson Product-Moment Correlation Coefficient was computed to establish the relationships between causal attributions dimensions and academic achievement (Table 2).

The correlation analysis indicated that attributing success to internal causes and failure to external causes was positively correlated to academic achievement. On the other hand, attributing success to external causes and failure to internal factors was negatively correlated to academic achievement. Since all the subdimensions of locus of causality had a statistically significant relationship with academic achievement and the hypothesized null hypotheses, there is no significant relationship between dimension of locus of causality, and academic achievement was rejected.

The correlation results also showed that attributing success to both controllable and uncontrollable causes was significantly positively correlated to academic achievement. There was also a significant but a negative correlation in attributing failure to both controllable and uncontrollable causes. This led to rejection of the second null hypothesis which stated that there is no significant relationship between causal attribution dimension of controllability and academic achievement.

The results further indicated that attributing success to stable causes and failure to unstable causes had a positive significant relationship to academic achievement while attributing success to unstable factors and failure to stable causes was significantly negatively correlated to academic achievement. This also led to the rejection of the third null hypothesis.

The correlations results revealed that all the twelve subdimensions of causal attributions were significantly correlated to academic achievement. However, the directions of the correlations varied, some portraying a positive and others a negative correlation to academic achievement. The associations also ranged from weak, $r$ $(583)=-0.10, p<0.05$, to moderate $r(583)=-0.34, p<0.01$.

To address the fourth research hypothesis, the null hypothesis was formulated:

$\mathrm{H}_{04}$ : there is no a significant prediction model of academic achievement from the causal attribution dimensions.

A multiple regression model was computed to find the extent to which the dimensions of causal attributions predict participants' academic achievement.

Table 3 shows the differential contribution of the dimensions of causal attributions in explaining the variation in academic achievement. Locus of causality accounted for $8 \%$ of the variance $(F(4,580)=0.08, p<0.01)$, controllability accounted for $17 \%$ of the variance $(F(2,578)=17, p<0.01)$ in academic achievement while stability only explained $0.1 \%$ $(F(2,576)=0.001, p=0.63)$ of the variance in academic achievement. To determine the predictive weight of each of the dimensions of causal attributions on academic achievement, the beta coefficients were examined and the findings are presented in Table 4.

The ANOVA analysis results presented in Table 5 indicated that the dimensions of causal attributions were significant predictors of academic achievement $(F(8,576)=$ $23.50, p<0.01$ ). The dimensions of internal locus of causality for success and failure and uncontrollable attributions for success and failure were excluded after the 12 dimensions were regressed. Their tolerance index was tolerance $=0$. This 
TABLE 1: Description of dimensions of causal attributions.

\begin{tabular}{lccccccc}
\hline Attributions & & Range & Min. & Max. & Mean & SD & Skewness \\
\hline \multirow{4}{*}{ Locus } & ILCAS & 38 & 22 & 60 & 45.14 & 5.82 & -0.560 \\
& ELCAS & 24 & 6 & 30 & 15.12 & 4.84 & 0.465 \\
& ILCAF & 42 & 16 & 58 & 37.78 & 5.93 & -0.095 \\
& ELCAF & 24 & 6 & 30 & 22.26 & 5.05 & -0.505 \\
\hline \multirow{5}{*}{ Controllability } & CAS & 21 & 9 & 30 & 20.09 & 3.72 & -0.199 \\
& UNCAS & 37 & 16 & 53 & 35.21 & 5.98 & 0.297 \\
& CAF & 22 & 6 & 28 & 15.31 & 4.27 & 0.356 \\
& UNCAF & 38 & 14 & 52 & 37.57 & 5.92 & -0.518 \\
\hline \multirow{5}{*}{ Stability } & SAS & 27 & 13 & 40 & 27.10 & 4.54 & 0.010 \\
& UNSAS & 36 & 9 & 45 & 33.16 & 4.69 & -0.737 \\
& SAF & 31 & 9 & 40 & 25.43 & 4.86 & -0.192 \\
& UNSAF & 28 & 17 & 45 & 34.62 & 5.39 & -0.454 \\
\hline
\end{tabular}

Note. $N=585$; Min = minimum; Max = maximum; SD = standard deviation; ILCAS = internal locus of causality attributions for success; ILCAF = internal locus of causality attributions for failure; ELCAS = external locus of causality attributions for success; ELCAS = external locus of causality attributions for failure; $\mathrm{CAS}=$ controllable attributions for success; CAF = controllable attributions for failure; UCAS= uncontrollable attributions for success; $\mathrm{UCAF}=$ uncontrollable attributions for failure; $\mathrm{SAS}=$ stable attributions for success; $\mathrm{SAF}=$ stable attributions for failure; USAS = unstable attributions for success; USAF = unstable attributions for failure.

TABLE 2: Correlation between dimensions of causal attribution of locus of causality, controllability, stability, and academic achievement.

\begin{tabular}{|c|c|c|c|c|c|c|c|c|c|c|c|c|}
\hline & 1 & 2 & 3 & 4 & 5 & 6 & 7 & 8 & 9 & 10 & 11 & 12 \\
\hline 1. ILCAS & - & & & & & & & & & & & \\
\hline 2. ILCAF & $0.19^{* *}$ & - & & & & & & & & & & \\
\hline 3. ELCAS & $-0.12^{* *}$ & $0.08^{*}$ & - & & & & & & & & & \\
\hline 4. ELCAF & $0.18^{* *}$ & -0.08 & $-0.51^{* *}$ & - & & & & & & & & \\
\hline 5. CAS & $0.71^{* *}$ & -0.03 & -0.04 & 0.03 & - & & & & & & & \\
\hline 6. CAF & $-0.13^{* *}$ & $0.65^{* *}$ & $0.13^{* *}$ & $-0.20^{* *}$ & $-0.11^{*}$ & - & & & & & & \\
\hline 7. UNCAS & $0.35^{* *}$ & 0.04 & $0.78^{* *}$ & $-0.39^{* *}$ & $0.59^{* *}$ & 0.04 & - & & & & & \\
\hline 8. UNCAF & 0.06 & $0.40^{* *}$ & $-0.34^{* *}$ & $0.71^{* *}$ & -0.04 & $0.55^{* *}$ & $-0.31^{* *}$ & - & & & & \\
\hline 9. SAS & $0.54^{* *}$ & 0.06 & $0.47^{* *}$ & $-0.20^{* *}$ & $0.78^{* *}$ & 0.01 & $0.86^{* *}$ & $-0.16^{* *}$ & - & & & \\
\hline 10. SAF & 0.01 & $0.50^{* *}$ & $-0.17^{* *}$ & $0.44^{* *}$ & -0.06 & $0.73^{* *}$ & $-0.17^{* *}$ & $0.91^{* *}$ & $-0.09^{*}$ & - & & \\
\hline 11. UNSAS & $0.59^{* *}$ & $0.26^{* *}$ & $0.43^{* *}$ & $-0.18^{* *}$ & $0.09^{*}$ & -0.04 & $0.40^{* *}$ & $-0.13^{* * * *}$ & $0.19^{* *}$ & -0.07 & - & \\
\hline 12. UNSAF & $0.36^{* *}$ & $0.58^{* *}$ & $-0.23^{* *}$ & $0.45^{* *}$ & 0.05 & $-0.13^{* *}$ & $-0.16^{* *}$ & $0.29^{* *}$ & -0.04 & 0.06 & $0.24^{* *}$ & \\
\hline 13. Acad. Ach & $0.15^{* *}$ & $-0.17^{* *}$ & $-0.11^{* *}$ & $0.16^{* *}$ & $0.32^{* *}$ & $-0.34^{* *}$ & $0.11^{*}$ & $-0.10^{*}$ & $0.19^{* *}$ & $-0.20^{* *}$ & $-0.12^{* *}$ & $-0.15^{* *}$ \\
\hline
\end{tabular}

${ }^{* *}$ Correlation is significant at the 0.01 level (2-tailed). ${ }^{*}$ Correlation is significant at the 0.05 level (2-tailed). $N=585 ; r=$ Pearson correlation; Acad. Ach = academic achievement; ILCAS = internal locus of causality attribution for success; ILCAF = internal locus of causality for failure; ELCAS = external locus of causality for success; ELCAF = external locus of causality for failure; CAS = controllable attribution for success; CAF = controllable attribution for failure; UNCAS = uncontrollable attribution for success; UNCAF = uncontrollable attribution for failure; SAS = stable attribution for success; $\mathrm{SAF}=$ stable attribution for failure; UNSAS = unstable attribution for success; UNSAF = unstable attribution for failure.

TABLE 3: Regression model for dimensions of causal attributions and academic achievement.

\begin{tabular}{lccccccccc}
\hline Model & \multirow{2}{*}{$R$} & $R$ square & Adjusted $R$ square & SE & \multicolumn{4}{c}{ Change statistics } \\
& & & & & $R$ square change & F change & df1 & df2 & Sig. F change \\
\hline 1 & $0.28^{\mathrm{a}}$ & 0.08 & 0.08 & 10.34 & 0.08 & 12.01 & 4 & 580 & 0.00 \\
2 & $0.49^{\mathrm{b}}$ & 0.25 & 0.24 & 9.36 & 0.17 & 64.41 & 2 & 578 & 0.00 \\
3 & $0.49^{\mathrm{c}}$ & 0.25 & 0.24 & 9.37 & 0.001 & 0.47 & 2 & 576 & 0.63 \\
\hline
\end{tabular}

$N=585,{ }^{\mathrm{a}}=$ locus of causality, ${ }^{\mathrm{b}}=$ controllability, ${ }^{\mathrm{c}}=$ stability.

meant that these dimensions could be perfectly predicted from the other causal dimensions. According to Table 4, the causal dimensions that significant predictors of academic achievement were external causal attributions for success $(\beta=0.23, \quad p<0.01)$; controllable attribution for success $(\beta=0.48, \quad p<0.01)$; controllable attributions for failure $(\beta=-0.34, \quad p<0.01)$; stable attributions for success $(\beta=-0.23, \quad p<0.05)$; unstable attributions for success $(\beta=-0.27, p<0.01)$; and unstable attributions for failure $(\beta=0.18, p<0.01)$. External locus of causality attributions for failure $(\beta=0.02, p=0.89)$ and stable attributions for failure $(\beta=0.06, p=0.67)$ were insignificant predictors of academic achievement.

Out of the eight dimensions of causal attributions, controllable attribution for success was found to be the critical positive predictor of academic achievement $(\beta=0.48$, $p<0.01)$. This implies that students may attribute their success or failure to different factors but attributing success to controllable factors will greatly improve their academic achievement. It was followed by controllable attributions to 
TABLE 4: Beta coefficients for dimensions of causal attributions on academic achievement.

\begin{tabular}{|c|c|c|c|c|c|c|c|c|c|}
\hline & \multicolumn{2}{|c|}{$\begin{array}{l}\text { Unstandardized } \\
\text { coefficients }\end{array}$} & \multirow{2}{*}{$\begin{array}{c}\text { Standardized coefficients } \\
\text { Beta }\end{array}$} & \multirow[t]{2}{*}{$\mathrm{T}$} & \multirow[t]{2}{*}{ Sig. } & \multicolumn{2}{|c|}{$95 \% \mathrm{CI}$} & \multicolumn{2}{|c|}{$\begin{array}{l}\text { Collinearity } \\
\text { statistics }\end{array}$} \\
\hline & B & SE & & & & LL & UL & Tol & VIF \\
\hline (Constant) & 46.01 & 4.53 & & 10.17 & 0.00 & 37.13 & 54.91 & & \\
\hline ELCAS & 0.47 & 0.16 & 0.23 & 2.87 & 0.00 & 0.15 & 0.78 & 0.21 & 4.71 \\
\hline ELCAF & 0.03 & 0.21 & 0.02 & 0.14 & 0.89 & -0.37 & 0.43 & 0.12 & 8.19 \\
\hline CAS & 1.3 & 0.25 & 0.48 & 5.28 & 0.00 & 0.82 & 1.78 & 0.16 & 6.40 \\
\hline CAF & -0.78 & 0.28 & -0.34 & -2.82 & 0.00 & -1.33 & -0.24 & 0.09 & 10.75 \\
\hline SAS & -0.49 & 0.23 & -0.23 & -2.18 & 0.03 & -0.94 & -0.05 & 0.13 & 8.12 \\
\hline SAF & 0.11 & 0.27 & 0.06 & 0.42 & 0.67 & -0.42 & 0.65 & 0.08 & 13.19 \\
\hline UNSAS & -0.56 & 0.10 & -0.27 & -5.50 & 0.00 & -0.77 & -0.36 & 0.57 & 1.77 \\
\hline UNSAF & 0.33 & 0.09 & 0.18 & 3.60 & 0.00 & 0.15 & 0.51 & 0.54 & 1.86 \\
\hline
\end{tabular}

Note. $\mathrm{CL}=$ confidence interval; $\mathrm{LL}=$ lower limit; $\mathrm{UL}=$ upper limit; ELCAS = external locus of causality for success; ELCAF = external locus of causality for failure; $\mathrm{CAS}=$ controllable attribution for success; $\mathrm{CAF}=$ controllable attributions for failure; $\mathrm{SAS}=$ stable attributions for success; $\mathrm{SAF}=\mathrm{ctable}$ attributions for failure; UNSAS = unstable attributions for success; UNSAF = unstable attributions for failure.

TABle 5: ANOVA for causal attributions.

\begin{tabular}{ccccccc}
\hline \multicolumn{1}{l}{ Model } & SS & Df & MS & F & Sig. \\
\hline & Regression & 14368.904 & 8 & 1796.113 & 23.50 & $0.00^{\mathrm{b}}$ \\
1 & Residual & 44031.096 & 576 & 76.443 & & \\
& Total & 58400.000 & 584 & & & \\
\hline
\end{tabular}

Note. $\mathrm{SS}=$ sum of squares, $\mathrm{MS}=$ mean square.

failure $(\beta=-0.34, p<0.01)$ which was a significant and negative predictor academic achievement.

A significant regression equation was obtained:

$$
\begin{aligned}
\tilde{y}= & 46.01+0.23(\mathrm{ELCAS}) \pm 0.2(\mathrm{ELCAF}) \\
& +0.48(\mathrm{CAS}) \pm 0.34(\mathrm{CAF}) \pm 0.23(\mathrm{SAS}) \\
& +0.06(\mathrm{SAF}) \pm 0.27(\mathrm{UNSAS}) \pm 0.06(\mathrm{SAF}) \\
\mathrm{R}^{2}= & 23.50 . p<0.01
\end{aligned}
$$

where $\tilde{y}=$ predicted academic achievement score, ELCAS $=$ external locus of causality for success, ELCAF $=$ external locus of causality for failure, CAS = controllable attributions for success; $\mathrm{CAF}=$ controllable attributions for failure, SAS $=$ stable attributions for success; $\mathrm{SAF}=$ stable attributions for failure, UNSAS = unstable attributions for success, and UNSAF = unstable attributions for failure. These results allowed for rejection of the second null hypothesis.

\section{Discussion}

In summary, majority of the respondents attributed both success and failure to internal, uncontrollable and unstable causes. These findings indicated that students tended to attribute success to factors within themselves. This shows they perceived to have control over their success, which could lead to improved performance. According to Weiner [12], attributing success to internal causes could lead to hopefulness since it meant success is within their control, which could make them unrelenting to academic tasks even when challenging. However, attributing success to unstable and uncontrollable reasons could be maladaptive since it may lead to lowered motivation, therefore leading to deficit in academic achievement. Attributing success to unstable factors is a learned helpless pattern since the students are not sure whether success will reoccur again. This scenario could decrease their motivation of working harder. This type of attribution is detrimental since it illustrated low self-efficacy meaning success is beyond their control and could lead to some level of helplessness.

Attributing failure to internal and uncontrollable factors may be detrimental. This was a defeatist approach since it portrayed their incapability to avoid failure and could lead to hopelessness. On the positive aspect, attributing failure to unstable factors is encouraging since the student believed that future success was probable. These findings may indicate that the students believed that failure was not consistent and would probably succeed in the subsequent achievement tasks. This was a healthy attributional pattern since it created room for positive potential change which is likely to lead to a high need achievement and a disposition to strife for better performance in the future. The current findings are in agreement with the study [11] which found that many students attributed their success on internal factors (ability and effort). They however negate the study whose findings were that the students attributed their failure to more external factors than internal [21].

The current results also indicated that there was significant relationship between causal attributions and academic achievement thus validating the Weiner theory [12] which asserted that people have diverse attributional style or specific reasons for explaining their academic outcomes based on three dimensions. The current findings are also consistent with the findings that a statistical significance relationship existed between attributional styles of the students and academic achievement [22]. However, the current study partly deviates from the study [10] that found no significant correlations among the causal attribution factors and academic attainment of students except for external attributions of failure that reported a significant correlation.

\section{Conclusion}

The results illustrate that causal attributions are correlates of academic achievement. Positive and negative significant 
relationships were found between the dimensions of causal attributions and academic achievement. This evidence will be important in understating how the dimensions of causal attribution correlate with academic achievement. The students employing inappropriate patterns of attribution develop persistent beliefs that success is not possible, and they lose motivation of putting more effort. Those employing a favorable attributional pattern increase their expectations for success in the future leading them to put more effort. Therefore, there is need to retrain students to make appropriate attributions. This may help them to fully realize their academic potential.

However, since this study comprised of the Kenyan population, generalization of the findings beyond this population may be limited. The study can be replicated in other countries. Data analysis was based mainly on correlational procedures, and therefore the results did not indicate the causes of the established relationships among the variables. The findings also gave limited knowledge about how each factor influences and/or is influenced by other factors and data were collected through self-report questionnaires, which may have introduced a degree of subjectivity in the results. The researcher recommends for use of other research designs and research instruments.

\section{Data Availability}

The data used to support the findings of this study are available from the corresponding author upon request.

\section{Conflicts of Interest}

The authors declare that they have no conflicts of interest.

\section{Acknowledgments}

The study was partially funded by the Kenyatta University School of Education Post Graduate Students Research Grant.

\section{References}

[1] UNESCO, Quality and Learning Indicators, UNESCO, Paris, France, 2019.

[2] Ministry of Education Science and Technology, KNEC 2016; KCSE Examination County Order of Merit, Ministry of Education Science and Technology, Nairobi, Kenya, 2016.

[3] F. Ford, "The effect of family poverty on children's academic achievement: parental discussion and neighbourhood poverty as mediating variables," Master's thesis, The State University of New Jersey, Newark, NJ, USA, 2011.

[4] A. M. Ireri, Academic identity status and achievement goal orientation as predictors of academic achievement among form three students in Embu County, Kenya, Ph.D. thesis, Kenyatta University, Nairobi, Kenya, 2015.

[5] A. O. Ismail, A. K. Mahmood, and A. Abdelmaboud, "Factors influencing academic performance of students in blended and traditional domains," International Journal of Emerging Technologies in Learning (iJET), vol. 13, no. 2, pp. 170-187, 2018.
[6] G. N. Kimani, A. M. Kara, and L. W. Njagi, "Teacher factors influencing students' academic achievement in secondary schools in Nyandarua, Kenya," International Journal of Education \& Research, vol. 3, no. 1, pp. 1-14, 2013.

[7] K. Bui, "Educational expectations and academic achievement among middle to high school students," Education, vol. 127, no. 3, pp. 328-331, 2007.

[8] N. Khattab, 'Students' aspirations, expectations and school achievement: what really matters?," British Educational Research Journal, vol. 41, no. 5, pp. 731-748, 2015.

[9] C. Lei, "On the causal attributions of academic achievement in college students," Asian Social Science, vol. 5, no. 8, pp. 87-96, 2009.

[10] A. Sambo and A. Mohammed, "Relationship of causal attribution and academic attainment among college of education students in North-Western Nigeria," Journal of Education Practice, vol. 6, no. 13, pp. 187-191, 2015.

[11] N. J. Solar, "Attribution of academic performance among third year and fourth year biology major students," Journal of Psychology and Psychotherapy, vol. 5, no. 5, pp. 1-6, 2015.

[12] B. Weiner, "Motivation from an attribution perspective and the social psychology of perceived competence," in Handbook of Competence and Motivation, A. Elliot and C. Dweck, Eds., pp. 73-84, Guilford Press, New York, NY, USA, 2005.

[13] B. Weiner, "The development of an attribution-based theory of motivation: a history of ideas," Educational Psychologist, vol. 45, no. 1, pp. 28-36, 2010.

[14] Y. Dong, R. H. Stupnisky, and J. C. Berry, "Multiple causal attributions: an investigation of college students learning a foreign language," European Journal of Psychology of Education, vol. 28, no. 4, pp. 1587-1602, 2013.

[15] A. Kaplan and Y. Yahia, "High school students' academic causal attributions in the cultural-political context of the Arab school system in Israel," Intercultural Education, vol. 28, no. 1, pp. 60-74, 2017.

[16] S. Batool and T. Akhter, "Causal attribution patterns of mainstream school students and their effect on achievement," Journal of Social Science, vol. 6, no. 2, pp. 131-154, 2012.

[17] A. K. Kitila and A. Jacquelein, "Perceived university students' attribution of their academic success and failure," Asian Social Science, vol. 8, no. 7, pp. 247-255, 2012.

[18] T. S. Onduso, "A comparison of teachers' and students attributions regarding Kiambu District," Master's thesis, Kenyatta University, Nairobi, Kenya, 2010.

[19] C. R. Kothari and G. Garg, Research Methodology: Methods and Techniques, New Age International (P) Ltd., Delhi, India, 5th edition, 2014.

[20] H. M. Leftcourt, C. L. Von Baeyer, E. E. Ware, and D. J. Cox, "The multidimensional multiattributional causality scale: the development of a goal, specific locus of control scale," $\mathrm{Ca}$ nadian Journal of Behavioral Science, vol. 11, no. 4, pp. 286-304, 1979.

[21] O. Abiodun and J. W. Owoyele, "Causal attributions and affective reactions to academic failure among undergraduates in the Nigerian Premier University of Education," European Journal of Scientific Research, vol. 52, no. 3, pp. 406-412, 2011.

[22] G. Cortés-Suárez and R. S. Janice, "Causal attributions for success or failure of students in college algebra, community college," Community College Journal of Research and Practice, vol. 32, no. 4-6, pp. 325-340, 2008. 


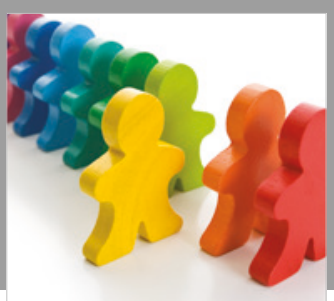

Autism

Research and Treatment
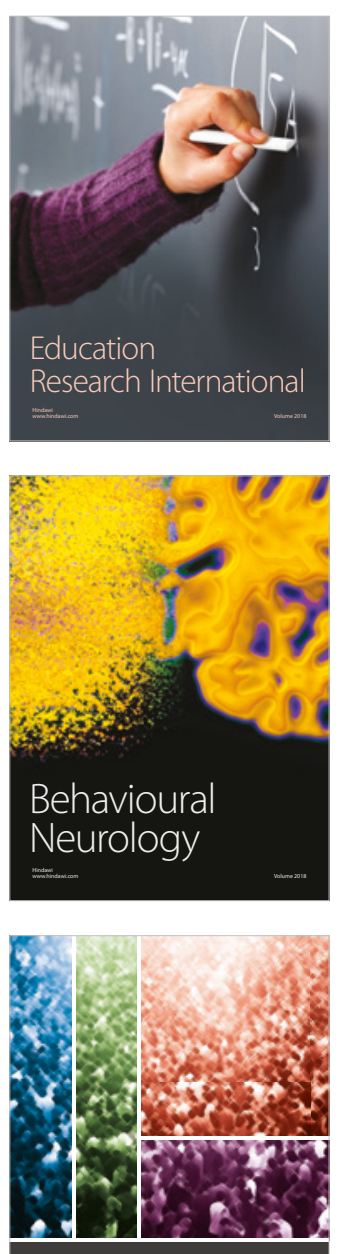

International Journal of

Population Research

$\underline{-m}$

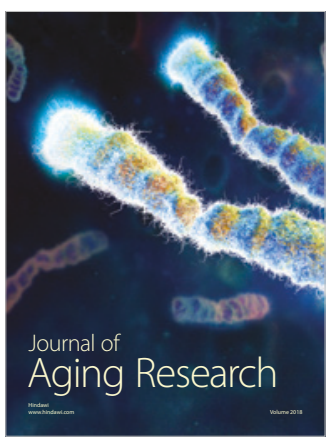

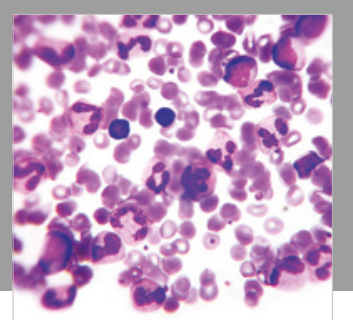

Pathology

Research International$$
=
$$

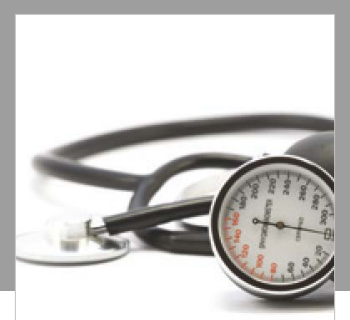

Nursing

Research and Practice

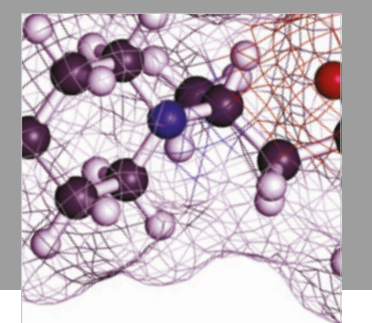

Pain

Research and Management

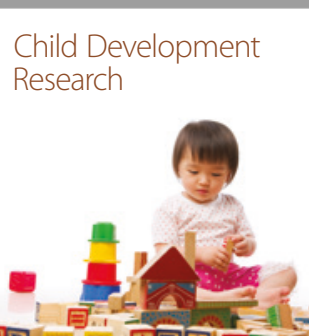

बाD

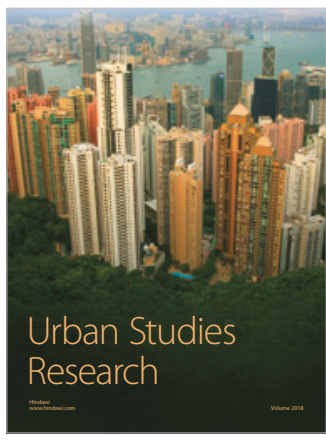

\section{Hindawi}

Submit your manuscripts at

www.hindawi.com
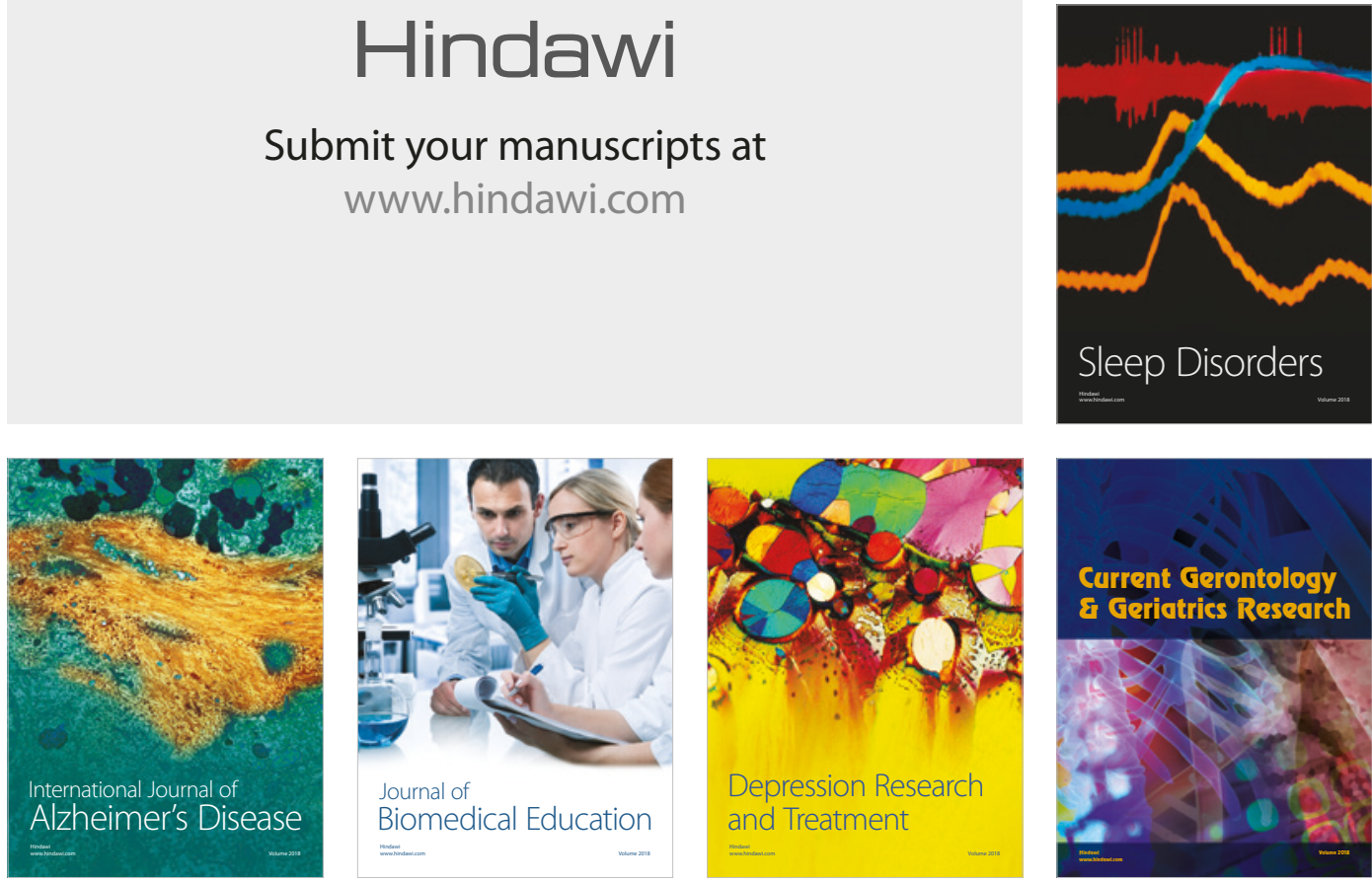

Journal of

Biomedical Education

$=$

smman

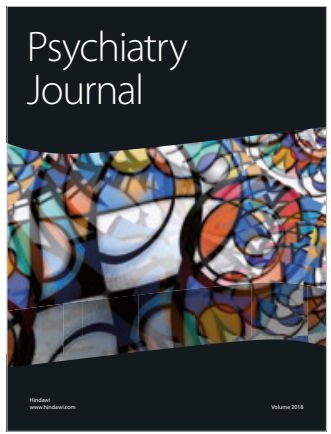

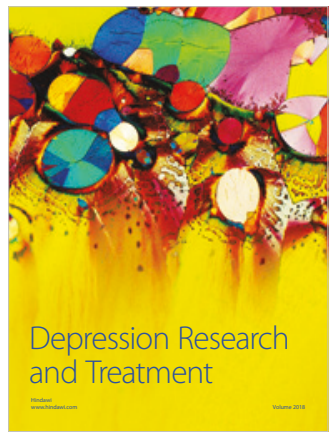
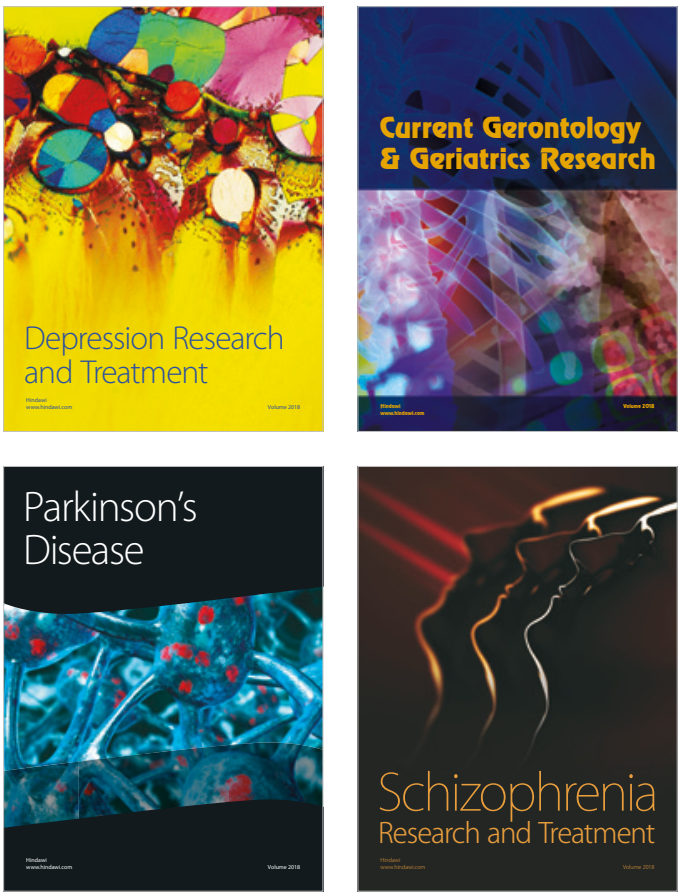